\title{
Cluster Control in Oligouranyl Complexes of $p$-t-Butylcalix[8]arene
}

\author{
Jack M. Harrowfield ${ }^{a}$ Mark I Ogden $^{b}$, Brian W. Skelton ${ }^{c}$ and Allan H. White ${ }^{c}$ \\ Received (in $X X X, X X X) X t h X X X X X X X X X 200 X$, Accepted $X$ th $X X X X X X X X X 200 X$ \\ First published on the web $X t h X X X X X X X X X 200 X$ \\ ${ }_{5}$ DOI: 10.1039/b000000x
}

Formation of uranyl ion complexes of $p$-t-butylcalix[8]arene by reaction of the calixarene with $\left[\mathrm{UO}_{2}(\mathrm{dmso})_{5}\right]^{2+}$ in the presence of various bases leads to the crystallisation of solids with interestingly different stoichiometry, involving both di- and tri-uranate oligomers bound to the calixarene in anionic species. In all, the calixarene hexa-anion is present in a virtually identical 10 conformation, suggesting that conformational preferences of the ligand must be a major factor controlling the form of the bound oxo-metal complex. Hydrogen-bonding to the anions does not appear to be prominent even in the presence of protonated amines and this may explain the formation of some remarkable cation/solvent/simple anion clusters found within the lattices.

\section{Introduction}

${ }_{15}$ Calixarenes are macrocyclic polyphenols that continue to attract attention as ligands that can support the formation of oligonuclear metal clusters. ${ }^{1}$ While much of this work involves the relatively simple calix[4]arenes, ${ }^{2-4}$ increasing ring size within the calixarene series is generally associated 20 with the complication of greater conformational flexibility. ${ }^{5,6}$ The energy minima possible are nonetheless influenced by the ring size and the nature of its constituents, so that every calixarene may be considered a source of a unique (if often large ${ }^{7}$ ) range of conformers. One consequence of this is that, 25 as a metal ion ligand, a given calixarene may facilitate particular modes of coordination with different metal ions and, more subtly, on different forms of one metal ion. In the particular case of $p$-t-butylcalix[8]arene, while the fairly subtle differences in its conformation associated with the 30 binding of transition metal ${ }^{5,8}$ or lanthanide $e^{9,10}$ ions have long been known, only more recently has a thorough study of the varied forms found in complexes of a single metal (tungsten) been made. ${ }^{5,8,} 11$ In their binuclear complexes of the lanthanides, both $p$-t-butylcalix[8]arene and calix[8]arene (at 35 least in the case of its $\mathrm{Eu}(\mathrm{III})$ complex ${ }^{12}$ ) adopt a twisted (chiral) conformation which allows two metal ions to be bound, two phenoxide- $O$ donors acting as bridges between them. Phenoxide- $O$ bridging is rare in known uranyl ion and other U(VI) complexes of calixarenes, ${ }^{13}$ a factor which might 40 be expected to favour the adoption of a different conformation of $p$-t-butylcalix[8]arene when bound to uranyl ion and indeed this appears to be so, with the three known examples ${ }^{14-16}$ involving a hydroxy-bridged diuranate unit bound to $p$ - $t$ butylcalix[8]arene in a (somewhat elliptical) pleated loop ${ }_{45}$ conformation, as found for the neutral free calixarene. ${ }^{17}$ While the protonation state of the diuranate $p$ - $t$-butylcalix[8]arene complex reportedly varies, in all cases the complex is anionic, and associated with cations that interact with the uranyl-O atoms, either through hydrogen bonds with triethylammonium 50 cations, ${ }^{14,15}$ or with one uranyl-O coordinating to the $\mathrm{K}$ atom in a $\left[\mathrm{K}(18 \text {-crown-6) }]^{+}\right.$unit. ${ }^{16}$ In the latter case, the uranate bridging hydroxyl acts as the donor in a hydrogen bond formed with a crown ether O atom. Despite these differences, the calixarene conformation is remarkably consistent, 55 suggesting that this moiety may be used as a predictable component in extended structures. In the present work, we have introduced diamine cations as the counter ion for the diuranate calix[8] arene complex anion, which can potentially act as both hydrogen bond donor or acceptor, depending on 60 the protonation state, in an effort to better understand which are the dominant binding modes of the complex anion. Upon addition of an excess of a stronger base, we have also found that this binuclear complex, obtained effectively by the fusion of two uranyl units on $p$-t-butylcalix[8]arene, appears to be ${ }_{65}$ capable of acting as a platform on which to bind a third uranyl unit, in this case involving binding to uranyl-O donors of both centres, with no substantive change in the calixarene conformation. The present work also provides further examples of U(VI) bound to calixarenes in seven-coordinate 70 (essentially pentagonal bipyramidal) species, the capacity of uranyl ion to bind three, four or five donor atoms equatorially appearing to be one means of adjusting to the demands of macrocyclic ligands. ${ }^{13}$

\section{Experimental}

\section{Synthesis}

Caution: Although no difficulties were experienced, metal perchlorate salts should be handled as potentially explosive materials.

${ }_{80}$ In a typical procedure, an approximately ten-fold excess of the appropriate base was added to a slurry of $p$ - $t$ butylcalix[8] arene $(80 \mathrm{mg}, 0.062 \mathrm{mmol})$ in acetonitrile (5 $\mathrm{mL})$. The mixture was stirred until all solids had dissolved, after which a solution of $\left[\left(\mathrm{UO}_{2}\right)(\mathrm{dmso})_{5}\right]\left(\mathrm{ClO}_{4}\right)_{2}{ }^{\ddagger 11}(110 \mathrm{mg}$, $\left.{ }_{85} 0.13 \mathrm{mmol}\right)$ in acetonitrile $(2 \mathrm{~mL})$ was added. The resulting solution was left to stand until the product crystallised, as redbrown crystals sometimes visibly contaminated with a pale yellow powder. Where the base used was $N, N$ diethylethylenediamine, $\sim 4 \mathrm{~mL}$ of dichloromethane was added 90 to the initial reaction mixture to slow deposition of the 
complex. Tetramethylammonium hydroxide was added as a $\sim 1$ mol L ${ }^{-1}$ methanolic solution.

\section{Structure Determinations}

Full spheres of CCD area-detector diffractometer data were 5 measured (Bruker AXS instrument, $\omega$-scans; monochromatic Mo $\mathrm{K} \alpha$ radiation, $\lambda=0.7107_{3} \AA$; T $c a .153 \mathrm{~K}$ ), yielding $N_{\mathrm{t}(\mathrm{otal})}$ reflections, these merging to $N$ unique $\left(R_{\text {int }}\right.$ cited) after 'empirical'/multiscan absorption correction (proprietary software), these being used in the 'full-matrix' refinements on ${ }_{10} F^{2}$, refining anisotropic displacement parameter forms for the non-hydrogen atoms, hydrogen atom treatment following a riding model; $N_{\mathrm{o}}$ reflections with $I>2 \sigma(I)$ were considered 'observed'. Reflection weights were: $\left(\sigma^{2}\left(F_{o}^{2}+(\mathrm{a} P)^{2}(+\mathrm{b} P)\right)^{-1}\right.$ $\left(P=\left(F_{o}^{2}+2 F_{c}^{2}\right) / 3\right)$; neutral atom complex scattering factors 15 were employed within the SHELXL 97 program. ${ }^{19}$ Pertinent results are given below and in the Tables and Figures, the latter showing 50\% probability amplitude non-hydrogen atom displacement envelopes, hydrogen atoms, where shown, having arbitrary radii of $0.1 \AA$. Individual divergences in 20 procedure are noted as 'variata'. Full .cif depositions (excluding structure factor amplitudes) reside with the Cambridge Crystallographic Data Centre, CCDC 773076 $773079,773902,773903$.

\section{${ }_{25}$ Crystal/refinement Data}

1a. ' $(\text { tmedaH })_{3}\left[\left((\mathrm{HO})\left(\mathrm{UO}_{2}\right)_{2}\right.\right.$ (calix $[8]-$ 6H)] $\cdot 5 \mathrm{MeCN} \cdot 1 / \frac{2}{\mathbf{d m s o}} \cdot \mathbf{2} \frac{1}{2} \mathrm{H}_{2} \mathbf{O}^{\prime} . \quad \mathrm{C}_{117} \mathrm{H}_{179} \mathrm{~N}_{11} \mathrm{O}_{16} \mathrm{~S}_{0.5} \mathrm{U}_{2}, M_{\mathrm{r}}=$ 2493.9. Triclinic, space group $P \overline{1}\left(C_{i}^{1}\right.$, No. 2), $a=21.445(1), b$ $=23.349(1), c=28.256(2) \AA, \alpha=89.153(8), \beta=76.002(2), \gamma$ ${ }_{30}=66.257(1)^{\circ}, V=12512(1) \AA^{3} . D_{\mathrm{c}}(Z=4)=1.32 \mathrm{~g} \mathrm{~cm}^{-3}$. $\mu_{\mathrm{Mo}}=2.7 \mathrm{~mm}^{-1}$; specimen: $=0.35 \times 0.15 \times 0.11 \mathrm{~mm} ;{ }^{\prime} T_{\min / \max }^{\prime}$ $=0.73 .2 \theta_{\max }=70^{\circ} ; N_{\mathrm{t}}=217684, N=102812\left(R_{\mathrm{int}}=0.056\right)$, $N_{\mathrm{o}}=40756 ; R 1=0.054, w R 2=0.15(\mathrm{a}=8), S=0.84$.

Variata. One of the $t$-butyl groups of molecule 1 , and one and 35 one-half of the cations were modelled as disordered over pair of sets of sites, occupancies set at 0.5 after trial refinement. Water molecule hydrogen atoms were not defined, here, nor in $1 \mathbf{b}$.

b. $\quad$ (tmpdaH $)_{2}(\operatorname{tmpdaH})_{0.5}\left[(\mathrm{HO})\left(\mathrm{UO}_{2}\right)_{2}(\right.$ calix $[8]-$

$\left.\left.{ }_{40} \mathbf{6 H}\right)\right] \cdot \mathbf{5 M e C N} \cdot \mathbf{5 H} \mathrm{H}_{2} \mathbf{O}^{\prime} . \quad \mathrm{C}_{115.5} \mathrm{H}_{180} \mathrm{~N}_{10} \mathrm{O}_{18} \mathrm{U}_{2}, \quad M=2472.8$. Triclinic, space group $P \overline{1}, a=18.110(3), b=18.202(3), c=$ 21.289(4) $\AA, \alpha=94.390(4), \beta=102.742(4), \gamma=103.199(4)^{\circ}$, $V=6604(3) \AA^{3} . D_{\mathrm{c}}(Z=2)=1.24_{3} \mathrm{~g} \mathrm{~cm}^{-3}$. $\mu_{\mathrm{Mo}}=2.5 \mathrm{~mm}^{-1}$; specimen: $=0.32 \times 0.24 \times 0.17 \mathrm{~mm} ;{ }^{\prime} T_{\min / \max }^{\prime}=0.71 .2 \theta_{\max }=$ ${ }_{45} 58^{\circ} ; N_{\mathrm{t}}=64740, N=32531\left(R_{\text {int }}=0.065\right), N_{\mathrm{o}}=18867 ; R 1=$ $0.066, w R 2=0.21(\mathrm{a}=0.128) ; S=0.97$.

Variata. Four of the $t$-butyl groups, and diverse cation and solvent components were modelled as disordered over pairs of sites (occupancies 0.5, isotropic displacement parameter 50 forms).

c.

' $\left[\left(\mathrm{H}_{2} \mathrm{~N}\left(\mathrm{CH}_{2}\right)_{2} \mathrm{NH}\left(\mathrm{C}_{2} \mathrm{H}_{5}\right)_{2}\right)_{2}\right]\left[\left(\mathrm{H}_{3} \mathrm{~N}\left(\mathrm{CH}_{2}\right)_{2} \mathrm{NH}\left(\mathrm{C}_{2} \mathrm{H}_{5}\right)_{2}\right)_{2}\right][(\mathrm{HO})($ $\left.\mathbf{U O}_{2}\right)_{2}$ (calix [8]-6H)] $\mathbf{C l}_{\mathbf{3}} \cdot \mathbf{2} \frac{1}{2} \mathbf{C H}_{2} \mathbf{C l}_{2}{ }^{\prime} \cdot \quad \mathrm{C}_{114.5} \mathrm{H}_{182} \mathrm{Cl}_{8} \mathrm{~N}_{8} \mathrm{O}_{13} \mathrm{U}_{2}$, $M=2638.3$. Monoclinic, space group $C 2 / c\left(C_{2 h}^{6}\right.$, No. 15), $a=$ ${ }_{55} 28.445(3), b=33.934(3), c=30.148(3) \AA, \beta=93.050(2)^{\circ}, V$ $=29059 \AA^{3} . \quad D_{\mathrm{c}}(Z=8)=1.20_{6} \mathrm{~g} \mathrm{~cm}^{-3} . \quad \mu_{\mathrm{Mo}}=2.4 \mathrm{~mm}^{-1}$; specimen: $=0.15 \times 0.13 \times 0.11 \mathrm{~mm} ;{ }^{\prime} T_{\min / \max }^{\prime}=0.73 .2 \theta_{\max }=$ $58^{\circ} ; N_{\mathrm{t}}=142456, N=37265\left(R_{\text {int }}=0.086\right), N_{\mathrm{o}}=17848 ; R 1=$ $0.062, w R 2=0.18(\mathrm{a}=0.095) ; S=0.90$.

${ }_{60}$ Variata. All cations and one of the solvent molecules were modelled as disordered over pairs of sites, occupancies 0.5 , as also a further solvent fragment (isotropic displacement parameters, idealized geometries). Remaining residues were assigned as fully or partially occupied water molecule oxygen 65 atom components.

2. ' $\left(\mathrm{NMe}_{4}\right)\left[(\mathrm{HO}) \mathrm{U}_{3} \mathrm{O}_{6}(\mathrm{calix}[8]-6 \mathrm{H})(\mathrm{dmso})_{2}\right] \cdot 6 \mathrm{CH}_{3} \mathrm{CN}^{\prime}$. $\mathrm{C}_{108} \mathrm{H}_{149} \mathrm{~N}_{7} \mathrm{O}_{17} \mathrm{~S}_{2} \mathrm{U}_{3}, M_{\mathrm{r}}=2595.6$. Monoclinic, space group $P 2_{1} / n\left(C_{2 h}^{5}\right.$, No. 14 (variant)), $a=16.668(2), b=21.255(2), c=$ 70 33.054(3) $\AA, \beta=100.644(2)^{\circ}, V=11509(2) \AA^{3} . D_{\mathrm{c}}(Z=4)=$

$1.49_{8} \mathrm{~g} \mathrm{~cm}^{-3} . \mu_{\mathrm{Mo}}=4.3 \mathrm{~mm}^{-1}$; specimen: $=0.50 \times 0.45 \times 0.14$ $\mathrm{mm} ;{ }^{\prime} T_{\min / \max }^{\prime}=0.40 . \quad 2 \theta_{\max }=58^{\circ} ; N_{\mathrm{t}}=110060, N=29059$ $\left(R_{\text {int }}=0.073\right), N_{\mathrm{o}}=20917 ; R 1=0.065, w R 2=0.18, S=1.10$.

Variata. The ligand $\mathrm{OH}$ hydrogen atom component 75 assignment was made on the basis of $\mathrm{O} . . \mathrm{O}$ distances $(\mathrm{O}(41) \ldots \mathrm{O}(5)$ 2.482(8), O(41)... (51) 2.486(8) $\AA$; others $>2.8$ $\AA)$. The only disorder resolved in the structure concerns solvent molecules $\mathrm{MeCN}(6,7)$, each modelled with occupancy 0.5 after trial refinement, and isotropic displacement 80 parameter forms (the latter also true of $\mathrm{MeCN}(5)$ ).

\section{Results and Discussion}

\section{Syntheses}

The synthesis of the uranyl $p$-t-butylcalix[8]arene complexes was carried out essentially as described previously, ${ }^{14}$ the 85 calixarene dissolving readily in acetonitrile upon addition of an excess of the relevant base. Red solutions formed upon addition of two equivalents of the uranyl salt (the dmso solvate of the perchlorate being used here as a convenient, compositionally well-defined source), and crystalline products 90 deposited upon standing. In all cases, elemental analysis was complicated by the co-deposition of a small amount of what was assumed to be uranyl hydroxide but the results of single crystal X-ray diffraction studies were sufficient to evaluate the structural features of interest. When 9 tetramethylethylenediamine (tmeda), and tetramethylpropylenediamine (tmpda) were used as the base, red crystalline materials, $\mathbf{1 a}$ and $\mathbf{1 b}$ respectively, were deposited in a form appropriate for diffraction studies. In the presence of $\mathrm{N}, \mathrm{N}$-diethylethylenediamine, the complex 1c 100 precipitated rapidly from acetonitrile solution as a microcrystalline powder. As was the case for all the materials reported here, efforts to recrystallise this product from acetonitrile resulted in dissociation of the complex. However, addition of dichloromethane to the initial reaction mixture 105 slowed the crystallization rate, resulting in a crystalline product (1c) of the required quality. The use of tetramethylammonium hydroxide as the base resulted in a darker red-brown solution, which slowly deposited deep redbrown crystals, 2, along with some white microcrystalline 10 powder that is likely to have been excess calixarene ligand, given the subsequently determined stoichiometry of the product. The crystals of $\mathbf{2}$ were suitable for single crystal Xray diffraction studies. 


\section{Structure Determinations}

1a-c. In all of these structures, anions of very similar form are found, comprising one ligand in association with a pair of oxygen-bridged uranyl species. There appears to be no 5 compelling reason why they should not be similarly protonated and so on the basis of the available evidence, they are all described as $\left[(\mathrm{HO})\left(\mathrm{UO}_{2}\right)_{2}\{\text { calix }[8]-6 \mathrm{H}\}\right]^{3-}$, with the uranium atom being seven-coordinated by the pair of oxooxygen atoms, together with the hydroxo- and four ligand 10 oxygen atoms in the equatorial plane. In the three nonisomorphous salts, the anions are found in association with assorted protonated amine cations, anions and solvent molecules. In 1a, two formula units devoid of crystallographic symmetry, make up the asymmetric unit of 15 the structure, in $\mathbf{1 b}$ and $\mathbf{1 c}$ one each. A typical anion, that of 1c, is depicted in Figure 1; geometries of the anions in all three salts are similar and are presented summarily in Table 1. The intraligand, interphenolic O...O distances are short for the pair straddling the UOU core $(\mathrm{O}(21) \ldots \mathrm{O}(31), \mathrm{O}(61) \ldots \mathrm{O}(71))$, 20 all less than $2.57 \AA$, whereas all others in all compounds are greater than $2.80 \AA$, suggesting those sites to be the locations of the pair of remaining phenolic hydrogen atoms, assigned in association with $\mathrm{O}(31,71)$. The overall anionic array appears, at first sight, to approach $\mathrm{mm}$ symmetry; on closer inspection 25 of the various descriptors (Table 1), however, it is clear that it is degraded to no more than 2 with many interesting divergences, presumably initially consequent upon the changes associated with protonation. A further determinant of various conformational subtleties is distortion imposed by the 30 fact that the angle at the central oxygen atom of the UOU array is not straight but typically $c a .145^{\circ}$, in consequence of which the quasi-linear uranyl units are not parallel but diverge appreciably from each other, as shown in the projection of Figure 1(b); the uranium atoms both lie slightly to the ${ }_{35}$ divergent side of the (rather good) (phenolic-O) $)_{8}$ 'plane' in each case, the anion overall forming a large, shallow ellipsoidal cup, with the central (a) set of aromatic rings somewhat everted. About the equatorial planes of the uranium atoms the sets of U-O distances associated with the 40 fully deprotonated set of 'outer' phenolic oxygen atoms $(\mathrm{O}(\mathrm{b}))$ are shorter than those 'inner' ones $(\mathrm{O}(\mathrm{a}))$ associated with the protonic hydrogen interactions, $\mathrm{U}-\mathrm{O}(0)$ lying in between. Among the angles, there are considerable differences in $\mathrm{O}(0)$ $\mathrm{U}-\mathrm{O}(1,2)$, these lying well below and well above $90^{\circ}$, 45 wrinkling the $\mathrm{O}_{5}$ 'equatorial' plane. $\mathrm{O}(1)-\mathrm{U}-\mathrm{O}(\mathrm{a}), \mathrm{O}(2)-\mathrm{U}-\mathrm{O}(\mathrm{b})$ are generally greater than $\mathrm{O}(1)-\mathrm{U}-\mathrm{O}(\mathrm{b}), \mathrm{O}(2)-\mathrm{U}-\mathrm{O}(\mathrm{a})$. Counter to the increasing trend in $\mathrm{U}-\mathrm{O}(\mathrm{b}, 0, \mathrm{a})$, we find the angles in the $\mathrm{O}_{5}$ plane to increase in the order $\mathrm{O}(0)-\mathrm{U}-\mathrm{O}(\mathrm{a}), \mathrm{O}(\mathrm{a})-\mathrm{U}-\mathrm{O}(\mathrm{b})$, $\mathrm{O}(\mathrm{b})-\mathrm{U}-\mathrm{O}\left(\mathrm{b}^{\prime}\right)$, the lack of correlation perhaps a consequence 50 of conformational dictates. With U-O(b) shorter than U-O(a), we find $\mathrm{U}-\mathrm{O}(\mathrm{b})-\mathrm{C}$ generally straighter than $\mathrm{U}-\mathrm{O}(\mathrm{a})-\mathrm{C}$, although the spreads are wide. The conformation of the calixarene ligand is remarkably constant across all compounds (compound 2, below, included). Despite the quite agreeable 55 coplanarity of the $\mathrm{O}_{8}$ donor set overall, it may be dissected into a pair of $\mathrm{O}_{4}$ arrays, each very closely planar, in association with the two uranium atoms. The latter diverge from the $\mathrm{O}_{4}$ plane slightly, toward the fifth equatorial donor, the bridging $\mathrm{O}(0)$, which lies out of the $\mathrm{O}_{4}$ plane by $c a .0 .4 \AA$. ${ }_{60}$ The two $\mathrm{O}_{4}$ planes subtend a dihedral angle of $c a$. $18^{\circ}$. (In 2 (below), the array is slightly flattened, the $\mathrm{O}_{4} / \mathrm{O}_{4}$ dihedral being $6.2(2)^{\circ}$ ). The similarities extend further to the pendant aromatic rings, those associated with ' $b$ ' sites having dihedral angles to the $\mathrm{O}_{8}$ plane of $c a .38-47^{\circ}$, while those associated 65 with the 'a' sites are larger, $c a$. $51-60^{\circ}$.

\section{Insert Table 1 here}

(a)

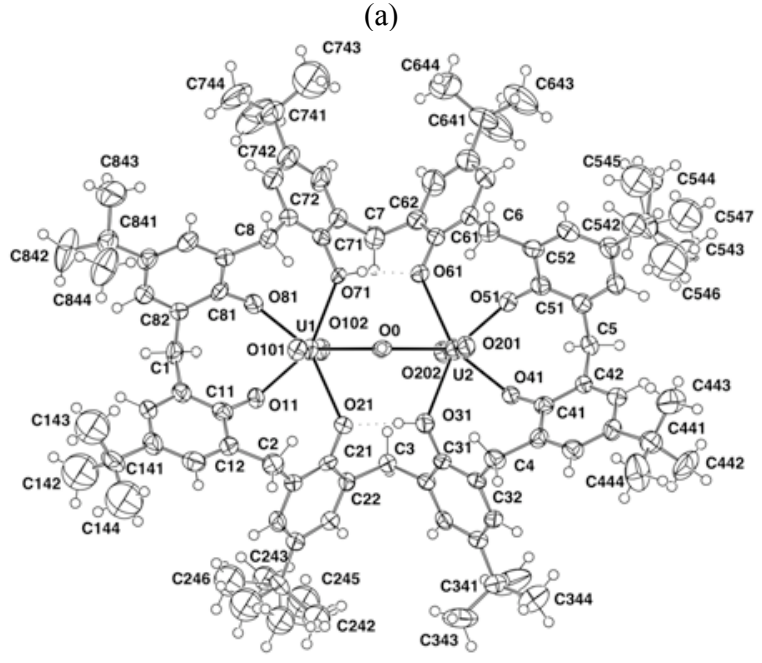

(b)

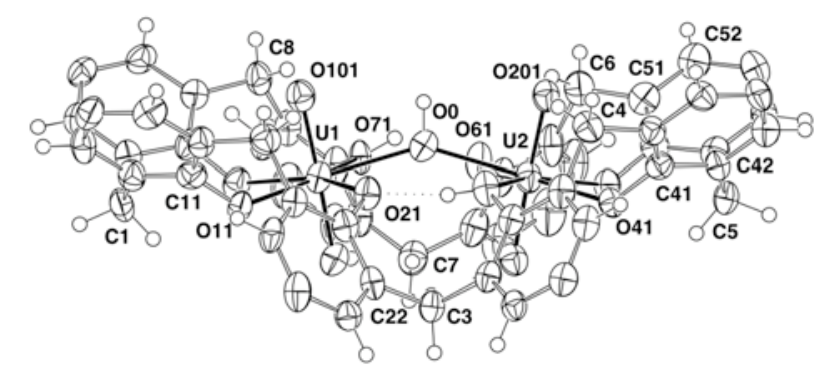

Fig. 1 (a) The anion of $\mathbf{1 c}$, projected normal to the ligand 'plane'. (b) Sideon view of the anion, devoid of $t$-butyl groups. In Table $1, \mathrm{O}(\mathrm{a})$ are the set $\mathrm{O}(21,31,61,71)$ and $\mathrm{O}(\mathrm{b}) \mathrm{O}(11,41,51,81)$.

As mentioned above, the previously reported diuranate 75 complexes of $p$-t-butylcalix[8]arene were found to have significant interactions between the counter cations and the uranyl-O atoms. In general, the binding of $\mathrm{U}(\mathrm{VI})$ to an incompletely deprotonated calixarene produces a complex species capable of acting as both a hydrogen-bond donor and a 80 hydrogen-bond acceptor, as well as as a Lewis base. Since multiple, inequivalent donor/acceptor sites may exist within a given species, one question that arises is that of how the size and conformation of the calixarene may influence its donor/acceptor properties. In the case of action as a Lewis ${ }_{85}$ base, for example, $\mathrm{Li}(\mathrm{I})$ is bound to the mono-U(VI) complex of $p$-t-butyl-tetrahomodioxacalix[4]arene through uranyl-O only, ${ }^{20}$ whereas it is bound to the di-U(VI) complex of $p$ - $t$ butylhexahomotrioxacalix[6]arene through U-bound phenoxide and an ether-O, with at most only a rather remote 90 contact to uranyl-O $(\sim 1 \AA$ longer than in the first complex $){ }^{21}$ The present work bears both upon the hydrogen-bond donor 
and acceptor properties of the seemingly rather rigid di-U(VI) derivative of the $p$-t-butylcalix[8]arene hexa-anion and upon its activity as a Lewis base towards extra U(VI). The first crystallographic study ${ }^{14}$ of this anionic complex was of its 5 triethylammonium salt, in which it appears that the cations form hydrogen-bonds to the two « divergent » uranyl-O atoms of the anion, a situation which differs remarkably from that in all other derivatives. Indeed, in the present examples, comparable interactions are remarkable only for their absence,

10 the only clear example being found in one of eight possible sites in 1a $(\mathrm{N}(601) \ldots \mathrm{O}(201), 2.886(6) \AA)$, the distance being comparable to those observed in the triethylammonium salts reported previously $\left(2.88(3),{ }^{14} 2.70(5)\right.$ and $\left.2.77(4) \AA^{15}\right)$. In the salt involving $\left[\mathrm{K}(18 \text {-crown-6) }]^{+}\right.$cations, ${ }^{16}$ it might be argued 15 that the binding of one potassium-crown unit to one of the divergent uranyl-O atoms inhibits acceptor hydrogen-bonding there and favours the secondary site of the bridging hydroxyl group for donor hydrogen-bonding (to crown ether-O) but while these interactions do not obstruct the second divergent 20 uranyl-O site, hydrogen-bond donation from the coordinated water molecules of the second potassium-crown unit occurs to the bound phenoxide- $\mathrm{O}$ atoms and poses the cation adjacent to the convergent uranyl-O atoms. In all three of the present ammonium salts of the diuranate complex, $\mathrm{NH}$... O hydrogen25 bonding appears to involve predominantly the bound phenoxide-O atoms and to occur from the side of the convergent uranyl-O atoms.

Of course, in all the known structures there are additional hydrogen-bond donors and acceptors present in the solvent 30 molecules forming part of the lattice. Water is intimately involved with the uranate core of the triethylammonium salt, one molecule bridging the two convergent uranyl-O atoms (though with rather long O... O distances) and three others forming a trimer unit which bridges, surprisingly, formally 35 only half-deprotonated bound phenolic-O units. The central oxygen atom of this trimer is within hydrogen-bonding distance of the hydroxyl-O bridging the two uranium centres and clearly there are aspects of the proton distribution in this complex which are not resolved by the X-ray structure 40 determination. Whether the acetonitrile molecules also present are involved in the hydrogen-bonding network is particularly uncertain. In the present examples, NH...O hydrogen-bonding involving exclusively the fully deprotonated, coordinated phenoxide-O atoms from the side adjacent to the convergent 45 uranyl-O atoms leads, in the salt formed with N,Ndiethylammonioethylamine cation 1c, to an exceptional structure involving capsules formed by two anionic calixarene units with their convergent uranyl-O faces oriented towards one another, in which are enveloped eight cations and six 50 adventitious chloride anions (Figure 2).

The structure of 1a also incorporates hydrogen-bond linked diuranyl calixarene units at the side adjacent to the convergent uranyl-O atoms (Figure 3). In this case there are only two linkages comprising a phenolate- $O \ldots \mathrm{N}, \mathrm{N}^{\prime} \ldots$ water- $O$, water${ }_{55} O \ldots$ phenolate- $O$ hydrogen-bond chain. The four remaining "external" phenolate $\mathrm{O}$-atoms are also involved in hydrogenbond interactions, to additional TMEDA N-atoms. Altering the added base to TMPDA results in a structure where these hydrogen-bond links are broken, but the disposition of the 60 calixarene complex anions and associated diamine molecules is remarkably similar (Figure 4). These results suggest that the hydrogen bond linkages formed in $\mathbf{1 a}$ and $\mathbf{1 b}$ may not be a strong contributing factor in the overall structure of these complexes. The significantly different results obtained for 1c 65 indicates that further exploration of the introduction of primary amines and/or the addition of chloride or similar anions in these systems could be of interest.

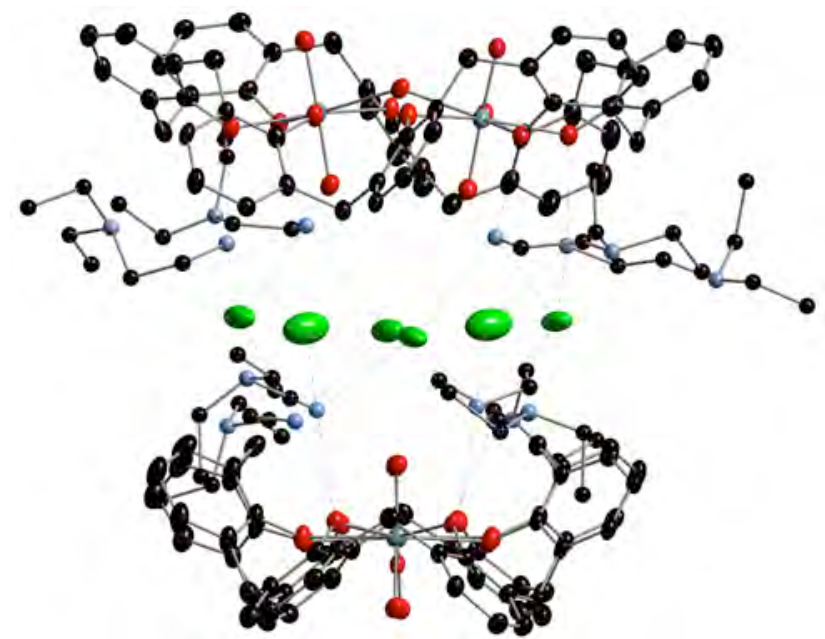

Fig. 2 A simplified view (omitting $t$-butyl groups and hydrogen atoms, 70 and removing thermal ellipsoids for the $\mathrm{Et}_{2} \mathrm{NCH}_{2} \mathrm{CH}_{2} \mathrm{NH}_{3}{ }^{+}$cations) of the hydrogen bonded capsule formed in $\mathbf{1 c}$ involving two calixarene complex anions encompassing eight $\mathrm{Et}_{2} \mathrm{NCH}_{2} \mathrm{CH}_{2} \mathrm{NH}_{3}{ }^{+}$cations and six chloride anions.

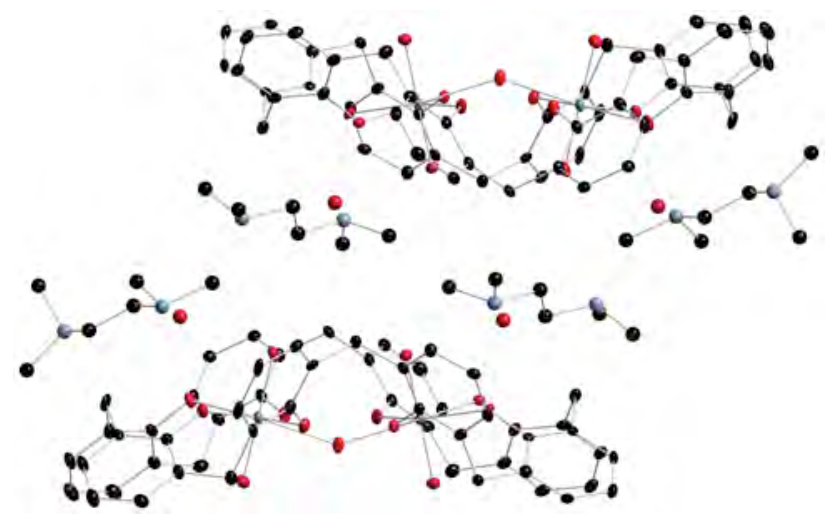

75 Fig. 3 A simplified view (omitting $t$-butyl groups and hydrogen atoms, and showing thermal ellipsoids for only the calixarene anions) of the hydrogen bonded links formed in 1a involving two calixarene complex anions, and associated water and TMEDA moieties. 


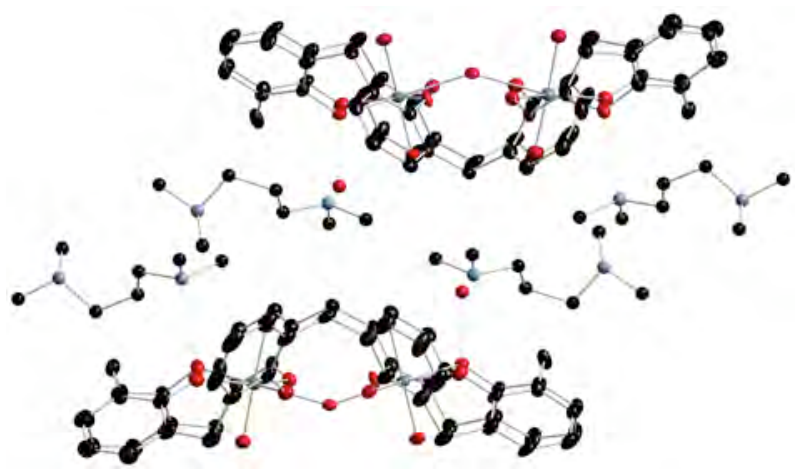

Fig. 4 A simplified view (omitting $t$-butyl groups and hydrogen atoms, and showing thermal ellipsoids for only the calixarene anions) of the structure formed in $\mathbf{1 b}$ involving two calixarene complex anions, and associated water and TMPDA moieties.

2. Despite the presence of the very heavy uranium atoms impeding hydrogen atom/protonation definition, the structures of the cationic and anionic substrate components are welldefined, with disorder evident in only one of the $t$-butyl 10 substituents of the ligand; solvent components, modelled as dmso (nicely ordered within the anion), and acetonitrile, disordered but uncoordinated, are insusceptible of protonation in the present ambience. One formula unit of the complex (plus accompanying solvent), devoid of crystallographic 15 symmetry, comprises the asymmetric unit of the structure. The cation is uncomplicated; the anion is a highly novel trinuclear form (Figure 5), which, apart from ligand and solvent peripheries, adopts a configuration which is a close approximation to $\mathrm{mm}$ symmetry - a 'horizontal' plane 20 containing the three uranium atoms and a 'vertical' one normal to it. The three uranium atoms are not equivalent: two $(\mathrm{U}(1,2))$ are each coordinated by one half of the calixarene ligand, the $\mathrm{U}(\mathrm{L} / 2)$ components being closely related by the putative 'vertical' mirror plane. The coordination 25 environments of the two uranium atoms are seven-coordinate (Table 1); the familiar pair of short U-O interactions is found, supporting an angle close to $180^{\circ}$, consistent with uranium(VI) as a "uranyl" species. The two distances are slightly different, the oxygen atom associated with the longer 30 bridging to bond with the third uranium $(\mathrm{U}(3))$. In the plane normal to the $\mathrm{O}=\mathrm{U}=\mathrm{O}$ axis, five-coordination is found: one bond is associated with the central oxygen atom $\mathrm{O}(0)$, which lies in the putative mirror plane, the other four associated with the sequence of four phenolic oxygen atoms from the relevant 35 half of the ligand. The aromatic rings of the ligand half form a shallow cone. The four U-O distances are divided into pairs: the two which lie near the mirror plane are longer than those distal to it. The reason would appear to lie in the proximity of the 'symmetry-related' oxygen atoms of the other 40 ligand half: $\mathrm{O}(11) \ldots \mathrm{O}(81), \mathrm{O}(41) \ldots \mathrm{O}(51)$ are only $2.482(8)$, $2.486(8) \AA$, suggesting that these locations may accommodate a pair of protonic hydrogen atoms, which, together with a further one on the central $\mathrm{O}(0)$ (thus hydroxide), provide a satisfying charge balance. However, it should be noted that

45 the central $\mathrm{O}(0)$ is essentially coplanar with the $U_{3}$ array, raising the question as to whether the hydrogen atom, if a central $\mathrm{OH}$ group, is disordered. Whereas $\mathrm{U}(1,2)$ are bridged by $\mathrm{O}(0)$, they bridge to $\mathrm{U}(3)$ by way of one of their oxo-O=U bonds as discussed above, $U(1) \ldots U(2)$ being longer than ${ }_{50} \mathrm{U}(3) \ldots \mathrm{U}(1,2)$, with a larger angle subtended at $\mathrm{O}(0), c f$. those at $\mathrm{O}(1,2)$. Thus, this cation is formed simply by $\mathrm{O}(0)$ and the pair of $\mathrm{UO}_{2}$ oxygen atoms to the same side of the ligand plane in the binuclear array of 1a-c, behaving as an equatorial, tridentate donor to an $\mathrm{O}_{2} \mathrm{U}(3)(\mathrm{O}-\mathrm{dmso})_{2}$ unit. The 55 coordination environment of the unique uranium atom, $\mathrm{U}(3)$, is thus also seven-coordinate with $\mathrm{U}(3)-\mathrm{O}(5,6)$ equivalent and subtending an angle close to $180^{\circ}\left(175.3(3)^{\circ}\right)$, but somewhat bent away from $\mathrm{O}(0)$ in the equatorial plane which carries five coordination sites, none of which involve a calixarene ligand. ${ }_{60}$ Two of the latter, to either side of $\mathrm{O}(0)$, are the oxo-oxygen atoms associated with $\mathrm{U}(1,2)$ as discussed above; the remaining $\mathrm{cis}$ pair of sites are occupied by a pair of $O$-dmso donors $\mathrm{O}(10,20)$ at distances typical of that ligand (e.g., $c f$. $\left[\mathrm{O}_{2} \mathrm{U}(\mathrm{dmso})_{5}\right]\left(\mathrm{ClO}_{4}\right)_{2},<>2.37(2) \AA{ }^{18} \mathrm{O}(0)$ is the most ${ }_{65}$ strongly bound atom in the equatorial arrays of all three uranium atoms.

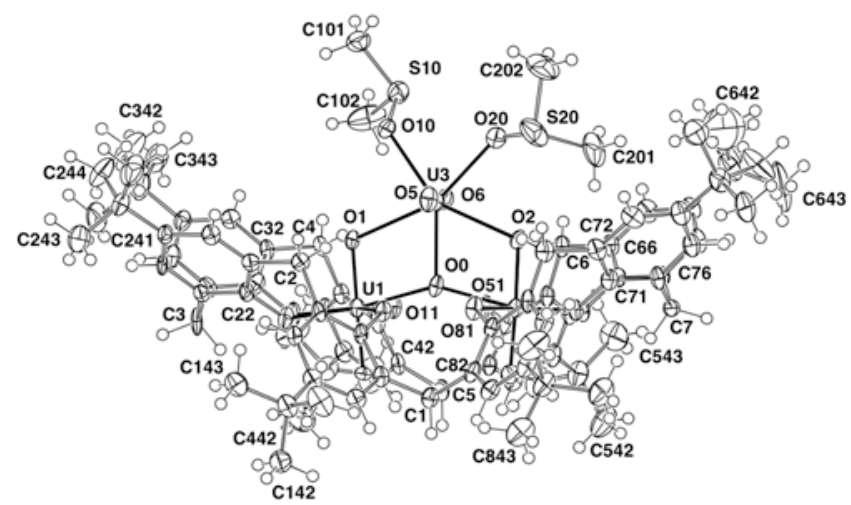

Fig. 5 The anion of 2 , projected normal to the $U_{3}$ plane. About $U(3)$ the sets $\mathrm{O}(\mathrm{a})$ and $\mathrm{O}(\mathrm{b})$ denote $\mathrm{O}(1,2)$ and $\mathrm{O}(10,20)$

70 Only a few examples of trinuclear U(VI) derivatives of calixarenes are known $22-24$ and each has certain unique characteristics. In the complex formed from $p$-t-butylhexahomotrioxacalix[6]arene, ${ }^{24}$ for example, each $\mathrm{U}$ centre is octahedral with two $\mu_{2}$ oxide ligands linking it to the other 75 two centres and an identifiable OUO (uranyl) entity not involved in bridging other than through hydrogen-bonding to an adjacent trinuclear species, while in the trinuclear derivative of $p$-t-butylcalix[6] $\operatorname{arene}^{22}$ a $\mu_{3}$ oxygen ligand links all three metal ions, each of which can be considered 80 pentagonal bipyramidal in form. The present case can be perhaps considered closer to the latter but one U(VI) has no direct interaction with the calixarene and its uranyl OUO entity lies perpendicular to the plane defined by the uranyl units of the "precursor » diuranate. Essentially, the diuranate ${ }_{85}$ species can be regarded as forming a tridentate $\mathrm{O}_{3}$ ligand to bind the third U(VI) centre, though the exact sequence of events leading to the trinuclear product is unknown. The effectiveness of uranyl-O as a Lewis base has been established structurally for a wide variety of heteronuclear complexes of 90 calixarenes $^{25}$ and it is clearly also of importance in the formation of many stoichiometrically simpler species. ${ }^{26} \mathrm{~A}$ striking feature of the lattice of $\mathbf{2}$ in comparison with those of 
1a-c is the absence of any conventional hydrogen-bonding interactions, although one methyl group of the tetramethylammonium cation does make a short contact (2.94(2) A) to a phenoxide-O. Surprisingly, given that they 5 are seen in simpler systems, ${ }^{27}$ there appear to be no significant cation- $\pi$ interactions involving the cal ixarene phenyl rings.

\section{Conclusions}

The results reported here illustrate that the structure of the diuranate $p$ - $t$-butylcalix[8] arene complex anion is remarkably 10 consistent despite significant changes in the associated species found in the crystal. As such, it is a potential component in 'crystal engineering' activities, with a particularly remarkable 'capsule'-like example found herein, albeit possibly requiring additional anions (chloride) along with an amine-derived 15 cation. The different arrays of solvent molecules found within the four lattices presently discussed provide fascinating hints as to the possible structuring of solvents around the ionic constituents in solution, although it would seem that hydrogen-bonding interactions are certainly not critical to the 20 maintenance of the forms of the polyuranate species in the solid state. The diuranate anion was also found to be capable of accommodating an additional uranyl cation, illustrating that this species is a versatile receptor that demands further attention to fully understand, and ultimately predict, its 25 behaviour as a component of supramolecular assemblies.

\section{Notes and references}

${ }^{a}$ Institut de Science et d'Ingénierie Supramoléculaires, Université de Strasbourg, 67083 Strasbourg, France.

${ }^{b}$ Department of Chemistry and Nanochemistry Research Institute, Curtin 30 University of Technology, GPO Box U 1987, Perth, WA 6845, Australia. Fax: +618 9266 2300; Tel: +6189266 2483; E-mail: m.ogden@curtin.edu.au

${ }^{c}$ Chemistry M313, School of Biomedical and Chemical Sciences,

University of Western Australia, Crawley, WA 6009, Australia.

35

$\uparrow$ Electronic Supplementary Information (ESI) available: Tables S1 - S3, providing details of the uranium coordination environments and of ligand conformational descriptors. See DOI: 10.1039/b000000x/

$40 \ddagger$ The previous $(295 \mathrm{~K})$ determination of the structure of $\left[\mathrm{UO}_{2}(\mathrm{O}\right.$ dmso) $\left.)_{5}\right]\left(\mathrm{ClO}_{4}\right)_{2}$ (space group $\left.\mathrm{Cc}\right)^{18}$ was of less than desirable precision, and, having material to hand, it was decided to attempt an improvement. It seems, however, that crystallisation of this complex is subject to subtle, possibly kinetic, influences. Addition of ethanol to a hot dmso solution of 45 the complex results in the precipitation of largely tabular crystals, as originally structurally characterised. Layering of ethanol onto a dmso solution and allowing mixing to occur by liquid-liquid diffusion provided, at least in one case, a mixture of tablets, thin plates, and needles, whereas vapour diffusion of ethanol into a dmso solution provided intergrown 50 clusters of fine needles. One of the very small, needle-like crystals was selected and found to be of a new phase (' $\beta$ '); one of the tablet crystals proved to be the original (' $\alpha$ ') form, although attempts to improve the determination of the latter by use of low-temperature were thwarted by crystal disintegration. Both structures were (re-) determined, the ' $\beta$ '-phase 55 at $c a .100 \mathrm{~K}$ with monochromatic $\mathrm{Cu} \mathrm{K}$ radiation $(=1.54184 \AA)$, the ' $\alpha$ 'phase at $c a .296 \mathrm{~K}$ with Mo K $\alpha$ radiation. In the latter, on this occasion, disorder was resolved in all ligands, generated by the familiar inversion at the sulfur.

$\mathbf{C}_{10} \mathbf{H}_{30} \mathbf{C l}_{2} \mathbf{O}_{15} \mathbf{S}_{5} \mathrm{U}, M_{\mathrm{r}}=859.6$. ' $\alpha$ '-phase (redetermination): Monoclinic, 60 space group $C \mathrm{c}\left(C_{s}^{4}, \# 9\right), a=22.2250(9), b=12.1538(3), c=11.9704(6)$ $\AA, \beta=113.670(5)^{\circ}, V=2961.4(2) \AA^{3} . D_{c}(Z=4)=1.92_{8} \mathrm{~g} \mathrm{~cm}^{-3} . \mu_{\mathrm{Mo}}=$
$6.1 \mathrm{~mm}^{-1}$; specimen: $0.33 \times 0.27 \times 0.16 \mathrm{~mm}^{3} ;{ }^{\prime} T_{\min / \max }=0.57$ ('analytical correction'). $2 \theta_{\max }=65^{\circ} ; N_{\mathrm{t}}=31414, N=10027\left(R_{\text {int }}=0.031\right), N_{\mathrm{o}}=$ 5306; $R 1=0.030, w R 2=0.081(\mathrm{a}=0.045) ; S=0.83, x_{\mathrm{abs}}=0.03 .\left|\Delta_{\max }\right|=$ 650.98 e $\AA^{-3}$.

' $\beta$ '-phase: Orthorhombic, space group $P 2_{1} 2_{1} 2_{1} \quad\left(D_{2}^{4}, \# 19\right), \quad a=$ $11.5740(9), b=12.0952(12), c=19.8514(14) \AA, V=2779.0(4) \AA^{3}$ (compatible with cell obtained on return of the specimen to roomtemperature). $D_{c}(Z=4)=2.05_{4} \mathrm{~g} \mathrm{~cm}^{-3} . \mu_{\mathrm{Mo}}=22.3 \mathrm{~mm}^{-1}$; specimen: $700.06 \times 0.03 \times 0.01 \mathrm{~mm}^{3} ; ' T_{\min / \max }=0.69$ ('analytical correction'). $2 \theta_{\max }=$ $135^{\circ} ; N_{\mathrm{t}}=24664, N=4954\left(R_{\text {int }}=0.128\right), N_{\mathrm{o}}=3963 ; R 1=0.042, w R 2=$ $0.072(\mathrm{a}=0.011) ; S=0.95, x_{\mathrm{abs}}=-0.036(8) .\left|\Delta_{\max }\right|=1.59 \mathrm{e} \AA^{-3}$.

$\mathrm{U}=\mathrm{O}$ were $1.733(5), 1.768(7)\left({ }^{\prime} \alpha^{\prime}\right) ; 1.755(7), 1.770(7) \AA\left('{ }^{\prime}\right), \mathrm{O}=\mathrm{U}=\mathrm{O}$ $172.4(4) ; 179.1(4)^{\circ}$ respectively. U-O(dmso) were $2.266(6)-2.371(4)(<>$ $752.34(4) \AA)(' \alpha ') ; 2.346(7)-2.396(7)(<>2.37(2) \AA$ (' $\beta$ '); the latter value is preferred because of the fully ordered nature of the structure and the lowtemperature determination. In $\left[\mathrm{UO}_{2}(\mathrm{O}-\mathrm{dmso})_{5}\right]\left(\mathrm{F}_{3} \mathrm{CSO}_{3}\right)_{2} \quad$ (J.M. Harrowfield, B.W. Skelton, A.H. White, C.R. Chimie, 2005, 8, 169), ligand disorder is also prevalent.

1. S. Siddiqui and P. J. Cragg, Mini Rev. Org. Chem., 2009, 6, 283-299.

2. N. de Silva, A. Solovyov and A. Katz, Dalton Trans., 2010, 39, 2194-2197.

3. G. Karotsis, S. Kennedy, S. J. Dalgarno and E. K. Brechin, Chem. Commun., 2010, 46, 3884-3886.

4. A. Bilyk, J. W. Dunlop, R. O. Fuller, A. K. Hall, J. M. Harrowfield, M. W. Hosseini, G. A. Koutsantonis, I. W. Murray, B. W. Skelton, A. N. Sobolev, R. L. Stamps and A. H. White, Eur. J. Inorg. Chem., 2010, 2010, 2127-2152.

90 5. C. Redshaw, Coord. Chem. Rev., 2003, 244, 45-70.

6. C. D. Gutsche, Calixarenes - An Introduction, Second edn., Royal Society of Chemistry, Cambridge, 2008.

7. I. Thondorf, in Calixarenes 2001, eds. Z. Asfari, V. Böhmer, J. Harrowfield and J. Vicens, Kluwer Academic Publishers, Dordrecht, 2001, pp. 280-295.

8. G. E. Hofmeister, F. E. Hahn and S. F. Pedersen, J. Am. Chem. Soc., 1989, 111, 2318-2319.

9. B. M. Furphy, J. M. Harrowfield, D. L. Kepert, B. W. Skelton, A. H. White and F. R. Wilner, Inorg. Chem., 1987, 26, 4231-4236.

100 10. P. Thuéry, M. Nierlich, J. M. Harrowfield and M. I. Ogden, in Calixarenes 2001, eds. Z. Asfari, V. Böhmer, J. Harrowfield and J. Vicens, Kluwer Academic Publishers, Dordrecht, 2001, pp. 561-582.

11. V. C. Gibson, C. Redshaw and M. R. J. Elsegood, Chem. Commun., 2002, 1200-1201.

105 12. S. Fleming, C. D. Gutsche, J. M. Harrowfield, M. I. Ogden, B. W. Skelton, D. F. Stewart and A. H. White, Dalton Trans., 2003, 33193327.

13. J. M. Harrowfield and G. A. Koutsantonis, in Calixarenes in the Nanoworld, eds. L. Baklouti, J. M. Harrowfield and J. Vicens, 110 Springer Verlag, London, 2006, pp. 197-212.

14. P. Thuéry, N. Keller, M. Lance, J. D. Vigner and M. Nierlich, Acta Crystallogr., Sect. C: Cryst. Struct. Commun., 1995, 51, 1570-1574.

15. P. Thuéry, N. Keller, M. Lance, J. D. Vigner and M. Nierlich, New J. Chem., 1995, 19, 619-625.

115 16. P. Thuéry, B. Masci, M. Takimoto and T. Yamato, Inorg. Chem. Commun., 2007, 10, 795-799.

17. C. D. Gutsche, A. E. Gutsche and A. I. Karaulov, J Inclusion Phenom, 1985, 3, 447-451.

18. J. M. Harrowfield, D. L. Kepert, J. M. Patrick, A. H. White and S. F. 120 Lincoln, J. Chem. Soc., Dalton Trans., 1983, 393-396.

19. G. M. Sheldrick, Acta Cryst., 2008, A64, 112-122. 
20. B. Masci and P. Thuery, Supramol. Chem., 2003, 15, 101-108.

21. P. Thuéry and B. Masci, Polyhedron, 2004, 23, 649-654.

22. X. Delaigue, C. D. Gutsche, J. M. Harrowfield, M. I. Ogden, B. W. Skelton, D. F. Stewart and A. H. White, Supramol. Chem., 2004, 16, 603-609.

23. P. C. Leverd and M. Nierlich, Eur. J. Inorg. Chem., 2000, 17331738.

24. P. Thuéry, M. Nierlich, J. Vicens and B. Masci, Dalton Trans., 2001, 3410-3412.

10 25. B. Masci and P. Thuery, CrystEngComm, 2007, 9, 582-590.

26. G. E. Sigmon, B. Weaver, K. A. Kubatko and P. C. Burns, Inorg. Chem., 2009, 48, 10907-10909.

27. J. M. Harrowfield, W. R. Richmond, A. N. Sobolev and A. H. White, J. Chem. Soc. Perkin Trans. 2, 1994, 5-9. 
Table 1. Complexed uranium coordination environments, 1a-c, 2

Ranges are given across the four cations defined within the three compounds 1a-c. $\mathrm{O}(0)$ is the U-O-U bridging hydroxyl oxygen atom, $\mathrm{O}(1,2)$ the $\mathrm{O}=\mathrm{U}=\mathrm{O}$ axial atoms $(\mathrm{O}(1)$ to the same side of the cation as $\mathrm{O}(0)), \mathrm{O}(\mathrm{a}, \mathrm{b})$ the families of phenolic oxygen atoms nearest, and, furthest from $\mathrm{O}(0)$. Counterpart values are given for the ligated binuclear component of the cation of 2 .

\begin{tabular}{|c|c|c|}
\hline Parameter & 1a-c (Range) & 2 \\
\hline \multicolumn{3}{|l|}{ Distances $(\AA)$} \\
\hline $\mathrm{U}-\mathrm{O}(0)$ & $2.333(3)-2.353(3)$ & $2.223(6), 2.235(5)$ \\
\hline $\mathrm{U}-\mathrm{O}(1)$ & $1.782(3)-1.795(3)$ & $1.839(6), 1.846(6)$ \\
\hline $\mathrm{U}-\mathrm{O}(2)$ & $1.784(3)-1.806(3)$ & $1.781(6), 1.791(6)$ \\
\hline $\mathrm{U}-\mathrm{O}(\mathrm{a})$ & $2.434(3)-2.613(3)$ & $2.398(6)-2.522(5)$ \\
\hline $\mathrm{U}-\mathrm{O}(\mathrm{b})$ & $2.208(3)-2.311(3)$ & $2.187(5)-2.340(6)$ \\
\hline $\mathrm{O}(\mathrm{a}) \ldots \mathrm{O}\left(\mathrm{a}^{\prime}\right)$ & $2.473(9)-2.561(5)$ & $2.473(9), 2.491(8)$ \\
\hline U...U' & $4.4724(4)-4.4955(7)$ & $4.2952(6)$ \\
\hline \multicolumn{3}{|l|}{ Angles (degrees) } \\
\hline $\mathrm{U}(1)-\mathrm{O}(0)-\mathrm{U}(2)$ & $144.2(1)-146.6(1)$ & $148.9(3)$ \\
\hline $\mathrm{O}(0)-\mathrm{U}-\mathrm{O}(1)$ & $84.5(1)-85.7(2)$ & $78.1(2), 77.0(2)$ \\
\hline $\mathrm{O}(0)-\mathrm{U}-\mathrm{O}(2)$ & $93.3(1)-96.4(1)$ & $100.3(2), 100.6(3)$ \\
\hline $\mathrm{O}(0)-\mathrm{U}-\mathrm{O}(\mathrm{a})$ & $64.9(1)-70.1(1)$ & $67.5(2)-71.2(2)$ \\
\hline $\mathrm{O}(\mathrm{a})-\mathrm{U}-\mathrm{O}(\mathrm{b})$ & $72.1(1)-76.2(1)$ & $71.1(2)-74.7(2)$ \\
\hline $\mathrm{O}(\mathrm{b})-\mathrm{U}-\mathrm{O}\left(\mathrm{b}^{\prime}\right)$ & $76.6(2)-79.7(2)$ & $74.2(2), 79.6(2)$ \\
\hline $\mathrm{O}(\mathrm{a})-\mathrm{U}-\mathrm{O}\left(\mathrm{a}^{\prime}\right)$ & $133.0(1)-134.9(1)$ & $138.8(2), 134.6(2)$ \\
\hline $\mathrm{O}(0)-\mathrm{U}-\mathrm{O}(\mathrm{b})$ & $136.9(1)-145.4(1)$ & $136.3(2)-142.3(2)$ \\
\hline $\mathrm{O}(\mathrm{a})-\mathrm{U}-\mathrm{O}\left(\mathrm{b}^{\prime}\right)$ & $149.6(1)-153.6(1)$ & $146.8(2)-154.2(2)$ \\
\hline $\mathrm{O}(1)-\mathrm{U}-\mathrm{O}(\mathrm{a})$ & $91.3(2)-94.8(1)$ & $90.7(2)-92.4(2)$ \\
\hline $\mathrm{O}(1)-\mathrm{U}-\mathrm{O}(\mathrm{b})$ & 87.6(1)-91.2(1) & $89.2(2)-93.3(2)$ \\
\hline $\mathrm{O}(2)-\mathrm{U}-\mathrm{O}(\mathrm{a})$ & $84.9(1)-88.1(1)$ & $87.2(3)-89.9(2)$ \\
\hline $\mathrm{O}(2)-\mathrm{U}-\mathrm{O}(\mathrm{b})$ & $88.7(1)-94.0(2)$ & $88.2(3)-92.8(2)$ \\
\hline $\mathrm{O}(1)-\mathrm{U}-\mathrm{O}(2)$ & $177.0(2)-179.6(1)$ & $178.4(3), 177.6(3)$ \\
\hline $\mathrm{U}-\mathrm{O}(\mathrm{a})-\mathrm{C}$ & $124.4(3)-133.2(3)$ & $128.2(5)-133.2(5)$ \\
\hline $\mathrm{U}-\mathrm{O}(\mathrm{b})-\mathrm{C}$ & $127.5(3)-143.5(4)$ & $132.4(5)-139.4(6)$ \\
\hline \multicolumn{3}{|c|}{ Interplanar dihedral angles (degrees) and atom deviations $(\AA)$} \\
\hline$\chi^{2}\left(\mathrm{O}_{8}\right)$ & $2 \times 10^{4}-3 \times 10^{4}$ & 853 \\
\hline$\delta \mathrm{O}_{\max }(\AA)$ & $0.276(4)-0.293(4)$ & $0.107(8)$ \\
\hline$\delta U(\AA)$ & $0.114(1)-0.170(1)$ & $0.123(2), 0.039(2)$ \\
\hline $\mathrm{O}_{8} / \mathrm{C}_{6}(\mathrm{a})($ deg.) & $51.3(1)-59.7(1)$ & $55.7(2), 58.6(3)$ \\
\hline $\mathrm{O}_{8} / \mathrm{C}_{6}$ (b)(deg.) & $38.1(1)-47.2(1)$ & $41.2(2), 47.5(2)$ \\
\hline$\chi^{2}\left(\mathrm{O}_{4}\right)$ & $10.5-478$ & $2.8,16.1$ \\
\hline$\delta \mathrm{O}_{\max }(\AA)$ & $0.007(4)-0.060(4)$ & $0.008(8), 0.020(8)$ \\
\hline$\delta \mathrm{O}(0)(\AA)$ & $0.337(5)-0.486(5)$ & $0.532(9), 0.556(9)$ \\
\hline$\delta U(\AA)$ & $0.050(1)-0.096(1)$ & $0.096(2), 0.023(1)$ \\
\hline $\mathrm{O}_{4} / \mathrm{O}_{4}$ (deg.) & $16.5(1)-19.2(1)$ & $6.2(2)$ \\
\hline
\end{tabular}

